\title{
Rotary Friction Welded C45 to 16NiCr6 Steel Rods: Statistical Optimization Coupled to Mechanical and Microstructure Approaches
}

\section{Youcef Belkahla ( $\square$ youcef_belkahla@hotmail.com )}

Science and Engineering Materials Laboratory (LSGM), USTHB BP 32 El Alia 16111, Bab Ezzouar.

\section{Azzeddine Mazouzi}

Science and Engineering Materials Laboratory (LSGM), USTHB BP 32 El Alia 16111, Bab Ezzouar.

\section{Islam LEBOUACHERA}

IPREM: Institut des Sciences Analytiques et de Physico-chimie pour l'Environnement et les Materiaux https://orcid.org/0000-0003-3365-3377

\section{Ammar Jabbar Hassan}

Université de Pau et des Pays de l'Adour, E2S UPPA, CNRS, IPREM, (Institut des Sciences Analytiques et de Physico-chimie pour l'Environnement et les Matériaux)

\section{Martin Fides}

Institute of Materials Research, Slovak Academy of Sciences

\section{Pavol Hvizdoš}

Institute of Materials Research, Slovak Academy of Sciences

Billel Cheniti

Research Center in Industrial Technologies, Chéraga 16014

\section{Djamel Miroud}

Science and Engineering Materials Laboratory (LSGM), USTHB BP 32 El Alia 16111, Bab Ezzouar.

\section{Research Article}

Keywords: Rotary Friction Welding, RSM methodology, Microstructure

Posted Date: May 18th, 2021

DOI: https://doi.org/10.21203/rs.3.rs-453778/v1

License: (c) (1) This work is licensed under a Creative Commons Attribution 4.0 International License. Read Full License

Version of Record: A version of this preprint was published at The International Journal of Advanced Manufacturing Technology on July 7th, 2021. See the published version at 
https://doi.org/10.1007/s00170-021-07597-z. 


\section{Abstract}

This work represents the production of dissimilar friction welded joints between C45 carbon steel and nickel-chromium alloy steel $16 \mathrm{NiCr} 6$. Central Composite Response Surface (RSM) methodology, optical microscopy, scanning electron microscopy (SEM), backscattered electron diffraction (EBSD) and bending test were performed for this study. Physicochemical characterization was used to reveal the welded joint microstructures. The bending test was done in order to measure the ultimate bending strength (UBS). As a conclusion, regarding the optimization of the parameters, friction time and the rotation speed were the most effective parameters on the joint strength. These parameters revealed that the maximum bending strength of $1406.892 \mathrm{MPa}$ can be obtained at a rotational speed of $2000 \mathrm{rpm}$, a friction pressure of 24.77 $\mathrm{MPa}$ and a friction time of 13 seconds. On the weld samples it was also noted that the particle size decreases significantly as the units of the parameters increase, which led to note that the optimization of these parameters converges towards an average particle size, where were found a good accommodation between hardness and young's modulus.

\section{Introduction}

Welding is often the weak point of these joint structures, especially if they are subjected to shock or vibratory loads. Some of these dissimilar joints require the use of input metals, and relatively expensive and difficult welding techniques. Most represent deficits in resistance to mechanical stresses caused by the melting of metals, which induces the brittleness of the weld bead [1-4]. Generally, medium carbon steels have average or poor weld-ability, although their very diverse use in the construction industry, due to their high mechanical strength. $\mathrm{C} 45$ and $16 \mathrm{NiCr} 6$ quality steels are extended and used in various industrial applications such as shipbuilding and the automotive industry. In fact, rotary friction welding (RFW) allows similar and dissimilar joints to be produced, which is today a solution for obtaining high welded joints [5-8]. Hence, RFW used for production of vehicle parts such as drive shafts, engine valves, pumps and compressor [9].

RFW creates joining by elevation of the temperature between the two surfaces in contact under effect of rotation speed and pressure, one of the piece is held in the stationary part while the other is chuck in moving part, the two pieces being in contact of each other until the rotation stopped rapidly, this period is called friction phase, then the pressure amplified to terminate the process and finish of welding joint, this period of time is called forge phase [10]. This technique has a several advantages such as: the absence of smoke and sparks, no filler metal, no shielding gas, a high welding rate for a short welding time, excellent mechanics, metallurgical properties, and a very resistant weld joint [8]. Contact between the two parts will trigger a flash, which will remove impurities and oxides from the interface which will subsequently promote the creation of a weld with excellent chemical and physical properties [7]. Thus, the thermal affected zone (TAZ) will expand to a lower thickness in friction welding compared to conventional welding [11]. 
Many studies on RFW and their parameters have been forgotten through experimental and analytical methods in trying to optimize favorable welding conditions. The basic parameters of RFW are: rotational speed $\mathrm{V}(\mathrm{rpm})$, friction time (s), friction pressure (MPa), forging time (s) and forging pressure (MPa). Table 1 presents a review of the literature for some of the previous authors operating conditions in RFW.

Table 1

Some welding parameters of previous research.

\begin{tabular}{|c|c|c|c|c|c|c|c|}
\hline Ref & Materials & $\begin{array}{l}\mathrm{D} \\
(\mathrm{mm})\end{array}$ & V (Rpm) & $P_{\text {friction }}(\mathrm{MPa})$ & $P_{\text {forging }}(\mathrm{MPa})$ & $\begin{array}{l}\text { Friction } \\
\text { time (s) }\end{array}$ & $\begin{array}{l}\text { Forging } \\
\text { time }(s)\end{array}$ \\
\hline [12] & $\begin{array}{l}\text { SUS304- } \\
\text { SUS304 }\end{array}$ & 25 & $\begin{array}{l}500-900- \\
1500\end{array}$ & $60-80-100$ & * & $\begin{array}{l}0.2 \text { to } \\
15\end{array}$ & * \\
\hline [13] & $304 S S-304 S S$ & 25 & 1500 & 80 & 80 & * & 6 \\
\hline [11] & $\begin{array}{l}\text { AISI 1040-AISI } \\
1040\end{array}$ & $\begin{array}{l}10- \\
12\end{array}$ & 2095 & * & * & $16-18$ & * \\
\hline [8] & $\begin{array}{l}\text { AISI 1010- } \\
\text { ASTM B22 }\end{array}$ & 20 & 2500 & 20 & 22 & $1-8$ & * \\
\hline [14] & $\begin{array}{l}\text { AISI 304L-4340 } \\
\text { steel }\end{array}$ & 12 & $\begin{array}{l}1500 \text { to } \\
2500\end{array}$ & 40 & 60 & 5 & * \\
\hline [7] & $\begin{array}{l}\text { AA1050- } \\
\text { AISI304 }\end{array}$ & 14.8 & 3200 & 2.1 & 1.4 & $7-32$ & 2 \\
\hline [15] & $\begin{array}{l}\text { AISI 304-AISI } \\
1060\end{array}$ & 20 & 2000 & $30-40-50$ & $50-70$ & 5 & * \\
\hline [16] & $\begin{array}{l}\text { AISI 316-AISI } \\
304\end{array}$ & 12 & 3000 & 130 & 260 & $\begin{array}{l}6.5-8.5- \\
10\end{array}$ & 5 \\
\hline [17] & $\begin{array}{l}\text { AISI 316-AISI } \\
316\end{array}$ & 12 & 3000 & 130 & * & $\begin{array}{l}6.5-8.5- \\
10\end{array}$ & * \\
\hline [18] & $\begin{array}{l}\text { AISI 304-AISI } \\
304\end{array}$ & 12 & 3000 & 130 & 260 & $\begin{array}{l}6.5-8.5- \\
10\end{array}$ & 5 \\
\hline \multicolumn{8}{|c|}{ D: sample diameter. } \\
\hline \multicolumn{8}{|c|}{$\mathrm{N}$ : rotation speed in road per minute. } \\
\hline
\end{tabular}

For optimizing friction welding parameters, there are two methods for optimizing these parameters. First one depends on single factor, changing one condition and fixing the others, while second one relies on the statistical method [19]. Several researchers used a design of experiments approach (DOE) in different applications [20-22] including a response surface methodology (RSM), when a response or more responses of interest are influenced by many parameters. 
However, Akbar Heidarzadeh [23] used response surface methodology of RSM for friction-stir welding. The results show that the most effective parameters for joint elongation and strength were tool rotational force and forging force, respectively. Optimization of these parameters showed that the maximum elongation of $55 \%$ and strength of $318 \mathrm{MPa}$ can be achieved at a rotational speed of $1000 \mathrm{rpm}$, advance speed of $58 \mathrm{~mm} / \mathrm{min}$ and an axial force of $03 \mathrm{kN}$. S.T. Selvamani and K. Palanikumar [24] have performed of RSM on the production of AISI 1035 carbon steel rods to optimize RFW parameters and achieve maximum tensile strength. The ANOVA method showed that a maximum expected tensile strength of $548 \mathrm{MPa}$ could be achieved under welding conditions of $1464 \mathrm{rpm}$ rotational speed, 03 seconds friction time, $86 \mathrm{MPa}$ friction pressure, 03 seconds forging time with $86 \mathrm{MPa}$ forging pressure. In the other hand, some works have studied RFWs of steels, similar and dissimilar joints [25-27].

Based on our knowledge, there is no study in open literature which reports the use of design of experiments and especially the full factorial approach to investigate the influence of parameters to measure the Ultimate Bending Strength (UBS) using a proper experimental design of carbon steel C45 with nickel-chromium alloy steel $16 \mathrm{NiCr} 6$ which improves the ultimate bending strength (UBS) of welded joint in first place. and provide the best clarification of the origins of the improvement in mechanical performance. Subsequently, the materials were characterized and evaluated by micro-structural approach and mechanical behaviour as a function of changes in RFW parameters using optical microscope (OM), SEM, electron backscatter diffraction (EBSD) and its effect on most significant parameter of welded joint.

\section{Experimental Procedure}

Medium carbon steel (C45) and Nickel chromium alloy structural steel for case hardening (16NiCr6) rods with $12 \mathrm{~mm}$ in diameters and $45 \mathrm{~mm}$ in length were used for present study. The chemical compositions and mechanical properties of the base metals are presented in Tables $2 \& 3$ respectively. The microstructure of the $\mathrm{C} 45$ and $16 \mathrm{NiCr} 6$ showed both a ferrite and pearlite structure with a difference in proportion.

Table 2

Chemical composition of the base metals (wt\%)

\begin{tabular}{|llllllll|}
\hline Material & $\mathbf{C}$ & $\mathrm{Mn}$ & $\mathrm{Si}$ & $\mathbf{P}$ & $\mathbf{S}$ & $\mathbf{N i}$ & $\mathrm{Cr}$ \\
\hline C45 & $0.45-0.50$ & 0.7 & 0.3 & $\varangle 0.035$ & $\otimes 0.035$ & - & - \\
\hline $16 \mathrm{NiCr6}$ & $0.14-0.17$ & $0.15-0.40$ & $0.40-0.60$ & - & - & $1.40-1.70$ & $1.40-1.70$ \\
\hline
\end{tabular}

Table 3

Mechanical properties of the base metals

\begin{tabular}{|lllll|}
\hline Material & $\mathrm{HV} 0.1$ & $\mathrm{Rm}\left(\mathrm{N} / \mathrm{mm}^{2}\right)$ & $\operatorname{Re}\left(\mathrm{N} / \mathrm{mm}^{2}\right)$ & $\mathrm{A} \%$ \\
\hline C45 & $180-210$ & $560-620$ & $275-340$ & $14-16$ \\
\hline 16NiCr6 & $200-230$ & $650-1400$ & $470-800$ & $9-11$ \\
\hline
\end{tabular}


Welding operations were performed using RFW machine [16-18]. It is has three phases AC and $3.5 \mathrm{~kW}$ power of motor with brake system, it supplies rotational speeds up to $3000 \mathrm{rpm}$ and maximum pressure of $300 \mathrm{MPa}$. C45 test pieces were chucked in rotary part and 16 NiCr6 were kept in stationary once. The objective of design of experiments approach is to simultaneously optimize the levels of these parameters in order to obtain the best system performance. It is a set of statistical and mathematical techniques that work by fitting a polynomial system equation to experimental data, which describes the behaviour of a set of data in order to make statistical predictions [28]. The following independently controllable process parameters were identified for the experiments: friction pressure $(F)$, friction time $(T)$ and rotational speed (V). Constant forging pressure (70 MPa) and forging time (3 s) are used in this study. The working ranges of all the selected parameters were determined by carrying out tests. One of the parameters was modified, while the others were kept at constant values. The working range of each welding parameter was determined by checking that the weld was free of visible defects. For experimental design was used JMP 13 software with ANOVA methods, where the upper and lower limits with different levels of the identified process parameters are shown in Table 4 . The selected design matrix is a central composite factorial design consisting of 16 sets of coded conditions [29]. All friction welding variables at the intermediate level (0) are the centre points and combinations of each of the welding variables at their lowest $(-1)$ or highest $(+1)$ level.

Table 4

Factors and levels used in the study

\begin{tabular}{|llllll|}
\hline Parameter & Notation & Unit & \multicolumn{4}{l|}{ Factor levels } \\
\hline & & & -1 & 0 & +1 \\
\hline Rotation speed $\left(\mathrm{X}_{1}\right)$ & $\mathrm{V}$ & $\mathrm{rpm}$ & 2000 & 2500 & 3000 \\
\hline Friction pressure $\left(\mathrm{X}_{2}\right)$ & $\mathrm{F}$ & $\mathrm{MPa}$ & 20 & 30 & 40 \\
\hline Friction time $\left(\mathrm{X}_{3}\right)$ & $\mathrm{T}$ & $\mathrm{s}$ & 9 & 11 & 13 \\
\hline
\end{tabular}

After welding, a flash of metal is observed for all specimens as shown in Fig. 1, this indicated that the surfaces of the joined materials were softened and plastically deformed, hence their solid-state welding has occurred [30]. This behaviour could be occurred due to increase in temperature induced by the elevation of friction time which softened the steel and favoured its plastic deformation. Figure $1 \mathrm{a}$, shows view of welds from different parameters used present RSM model. The weld joints show similar macroscopic aspects with different flash formation size as the change of the welding parameters from minimum to maximum units. Flash formation in the rotary friction welding process was due to increase in parameters and the generated heat which was higher at the periphery than in the central area of the welded joint [31].

Mechanical bending test based on ASME BPVC Section IX- 2017 (PP 38) was conducted to show the flexion properties and ultimate bending strength (UBS) of the joints. For this purpose, the longitudinal flexion samples were cut with Molybdenum wire perpendicular to the weld line with geometry of $40 \mathrm{~mm}$ 
(length), $6 \mathrm{~mm}$ (width), and $3 \mathrm{~mm}$ (thickness), the schematic of the bending specimens is illustrated in Fig. 1d. Bending tests were conducted on TIRA test 2300 equipment with a bending rate of $1 \mathrm{~mm} / \mathrm{min}$ and automatically stop at $8 \mathrm{~mm}$ of bending. It is notable that five bending tests were carried out for each FRW parameters. The 16 experimental runs allowed for the friction welding parameters combination, the experimental and predicted ultimate Bending strength (UBS) and the graphs are summarized in Table 5 and Fig. 2 respectively.

Table 5

Design layout including experimental and predicted values

\begin{tabular}{|c|c|c|c|c|c|c|c|}
\hline \multirow[t]{2}{*}{ No } & \multirow[t]{2}{*}{ Samples } & \multicolumn{3}{|c|}{ Coded value of parameters } & \multicolumn{2}{|l|}{ UBS (MPa) } & \multirow[t]{2}{*}{ crack } \\
\hline & & $x_{1}$ & $x_{2}$ & $X_{3}$ & Experimental & predicted & \\
\hline 1 & S10 & 1 & -1 & -1 & 1295 & 1288.50862 & \\
\hline 2 & S6 & -1 & 1 & -1 & 1109 & 1096.80862 & \\
\hline 3 & S8 & 0 & 1 & 0 & 1144 & 1165.16552 & \\
\hline 4 & S4 & 0 & 0 & 0 & 1202 & 1223.06897 & \\
\hline 5 & S5 & -1 & 0 & 0 & 1267 & 1245.16552 & \\
\hline 6 & S16 & 1 & 0 & 0 & 1302 & 1311.76552 & \\
\hline 7 & S1 & -1 & -1 & -1 & 1134 & 1145.90862 & \\
\hline 8 & S3 & 0 & 0 & -1 & 1158 & 1174.36552 & \\
\hline 9 & S7 & 1 & 1 & -1 & 1265 & 1255.40862 & * \\
\hline 10 & S14 & 1 & -1 & 1 & 1358 & 1373.20862 & \\
\hline 11 & $\mathrm{~S} 2$ & 0 & 0 & 0 & 1220 & 1223.06897 & \\
\hline 12 & S15 & -1 & 1 & 1 & 1323 & 1332.50862 & \\
\hline 13 & $\mathrm{~S} 12$ & -1 & -1 & 1 & 1386 & 1398.60862 & \\
\hline 14 & S13 & 0 & -1 & 0 & 1248 & 1214.76552 & \\
\hline 15 & s9 & 1 & 1 & 1 & 1332 & 1323.10862 & \\
\hline 16 & S11 & 0 & 0 & 1 & 1363 & 1334.56552 & * \\
\hline
\end{tabular}

The microstructure of the joints was first examined by using an optical microscope (OM). The OM sample were sectioned from the joints parallel to the direction of welding Fig. 1c, and then prepared by mechanical polishing until using OP-S $0.04 \mathrm{um}$, chemical etching was done with a solution of $1 \mathrm{ml}$ nitric acid in $100 \mathrm{ml}$ ethanol. SEM and EDX ZEISS Gemini SEM 300 were used to observe the fractured 
surfaces. For EBSD used a SEM Jeol JSM 7000F on two samples S3(00-1) and S11(00 + 1) were prepared by ionic polishing in order to study the evolution of the grain structure.

Nano-indentation measurements were done by Anton Paar NHT-3 nano-indenter with a Berkovich tip using a $50 \mathrm{mN}$ applied load. The indenters were carried out in the welding centre, while the hardness and Young's modulus were automatically calculated taking into account the standards of the instrumented indentation using the Oliver-Pharr method [32]. Scratch tests were carried out on Bruker UMT equipment, across the welding interface at a constant load of $20 \mathrm{~N}$ with a scratch length of $10 \mathrm{~mm}$ and a speed of $0.1 \mathrm{~mm} / \mathrm{s}$. While Vickers microhardness $\mathrm{H}_{\mathrm{V} 0.1}$ was achieved by WILSON VH3300 with 70 points of measurements start from $\mathrm{C} 45$ to $16 \mathrm{NiCr} 6$ crossing the welding interface.

\section{Results And Discussion}

\subsection{Factorial design of experiments:}

\subsubsection{Model fitting}

The evaluation of effective process variables on the UBS (MPa) were performed based on the Composite Central design (CCD) matrix with two replicated points. The design points, experimental and predicted results of (UBS) are represented in the Table 5.

To minimize the effects of uncontrolled factors, the experiments were performed in a random sequence too. Present study have found that the relationship between Ultimate bending strength (UBS) of the friction welded samples joints is a function of the friction welding parameters such as a Rotational speed (X1), friction pressure (X2) and Friction time (X3) which can be expressed as [24]:

$\mathrm{UBS}=\left\{\mathrm{X}_{1} ; \mathrm{X}_{2} ; \mathrm{X}_{3}\right\}$

The second-order polynomial equation is used to represent the response surface Ultimate bending strength given by:

UBS $=b_{0}+\sum b_{i} x_{i}+\sum b_{i i} x_{i}^{2}+\sum b_{i j} x_{i} x_{j}$

For three factors, the chosen polynomial model can be expressed as:

UBS $=b_{0}+b_{1}\left(X_{1}\right)+b_{2}\left(X_{2}\right)+b_{3}\left(X_{3}\right)+b_{12}\left(X_{1} X_{2}\right)+b_{13}\left(X_{1} X_{3}\right)+b_{23}\left(X_{2} X_{3}\right)+b_{11}\left(X_{1}^{2}\right)+b_{22}\left(X_{2}^{2}\right)+b_{33}\left(X_{3}{ }^{2}\right)$

Where $\left(b_{0}\right)$ is the average of the responses and $b_{1}, b_{2}, b_{3} \ldots b_{33}$ are regression coefficients [33] that depends on the respective linear, interactive, and squared terms of the factors. The significance of each coefficient is determined by ' $F$ ' and ' $p$ ' values, which are listed in Table 6.

Table 6 ANOVA analysis of UBS (MPa) 


\begin{tabular}{|llclll|}
\hline Source & Sum of squares & $D_{F}$ & Mean square & F-ration & $p$-value \\
\hline Model & 111129.13 & 9 & 12347.7 & 15.9716 & $0.0016^{*}$ \\
\hline Error & 4638.62 & 6 & 773.1 & & \\
\hline C.Total & 115767.75 & 15 & & & \\
\hline
\end{tabular}

${ }^{*} p \otimes 0.05$

The value of the coefficient is calculated using the Design Expert Software. The quadratic model proved to be adequate for predicting the response given by the following Equations:

UBS $(\mathrm{MPa})=1223.06+33.3 * \mathrm{X}_{1}-24.8 * \mathrm{X}_{2}+80.1 * \mathrm{X}_{3}+4 *\left(\mathrm{X}_{1} * \mathrm{X}_{2}\right)-42 *\left(\mathrm{X}_{1} * \mathrm{X}_{3}\right)-4.25\left(\mathrm{X}_{2} * \mathrm{X}_{3}\right)+55.39 * \mathrm{X}_{1}{ }^{2-}$ $33.1 * X_{2}{ }^{2}+31.39 * X_{3}{ }^{2}$

In Eq. (4) can show the interactions between variables. They have significant effects on the response; the results are therefore presented and discussed. The statistical significance of Eq. (4) is presented in Table 7. From Table 6 , respectively the terms mean square, degree of freedom $\left(D_{F}\right)$ and sum of squares are defined as the variance estimation of the model, the number of model and total sum of squares for model. The ANOVA (F-test) shows that the second order model (quadratic polynomial) corresponds to the experimental data also. The $p$-value is a quantitative measure to report the result of a hypothesis test. This is the probability that the statistical test is at least as extreme as those observed since the null hypothesis is true. Based on the results of the Fig. $3, R^{2}$ it was equal to 0.96 indicating the model to satisfy well the response [24].

The degree of freedom $\left(D_{F}=15\right)$ in Table 6 indicates the total number of model terms, including the intercept minus one. It is clearly that the model is highly significant, as suggested by the model $F$-value (15.9716) and a low probability value ( $p$-value $=0.0016)$. If $p$-value is less than or equal to the chosen significance level alpha value of 0.05 , the test suggests that the observed data are inconsistent with the null hypothesis. Therefore, it's must be rejected and the factor effect is significant [34]. It appears from Table 7 the linear effects of rotation speed; friction pressure and time are significant. The same trend was observed for the interactions effects between these factors, which confirms that the model is highly significant with the $p$-value of $0.0016<0.05$ [35-37] and $F$-value of 15.9716 cited in ANOVA analysis in Table 6.

In current study have analyzed the results obtained which appear in the Table 7, it can be conclude that friction time $\left(X_{3}\right)$ is the most important parameter for the overall UBS (MPa) with a high t-ratio: 9.11, the parameter exerts a stronger influence on the response (UBS). Secondly, rotation speed can be the second important influencer parameter phenomenon with a t-ratio: 3.79. Friction pressure was the least significant parameter with a t-ratio: -2.82. The interactions of $\left(X_{1}\right.$ and $\left.X_{3}\right)$ (with a high $t$-ratio: -4.27$)$ was the most significant compared to the other combinations $\left(X_{2}\right.$ and $\left.X_{3}\right)$ and $\left(X_{1}\right.$ and $\left.X_{2}\right)$. The latter was the 
least significant (with a tratio: 0.41). The negative sign means that the factors and the response are inversely proportional.

Table 7 Estimated regression coefficients.

\begin{tabular}{|c|c|c|c|c|}
\hline Parameter & Estimate & Standard Error & t-ratio & $p$-value \\
\hline Intercept & 1223.069 & 13.16365 & 92.91 & Q.0001* \\
\hline$x_{1}(V)$ & 33.3 & 8.79 & 3.79 & $0.0091 *$ \\
\hline$X_{2}(F)$ & -24.8 & 8.79 & -2.82 & $0.0303^{*}$ \\
\hline$X_{3}(T)$ & 80.1 & 8.79 & 9.11 & ه.0001* \\
\hline$x_{1} * x_{2}$ & 4 & 9.83 & 0.41 & 0.6982 \\
\hline$x_{1} * x_{3}$ & -42 & 9.83 & -4.27 & $0.0052^{*}$ \\
\hline$x_{2} * x_{3}$ & -4.25 & 9.83 & -0.43 & 0.6806 \\
\hline$X_{1} * X_{1}$ & 55.39 & 17.12 & 3.23 & $0.0178^{*}$ \\
\hline$X_{2} * X_{2}$ & -33.10 & 17.12 & -1.93 & 0.1014 \\
\hline$X_{3} * X_{3}$ & 31.39 & 17.12 & 1.83 & 0.1164 \\
\hline
\end{tabular}

On the other hand, the difference between experimental and predicted values is illustrated on UBS in Fig. 4. There are points below and above straight line called point of line zero; the positive values observed on the residual plot indicate a low predictive result. While, negative values imply that the prediction was high; a value of zero means that the prediction is accurate since there is a total superposition between experimental and predicted values. The residual plot for UBS following Eq (4) shows a random pattern. This indicates that the distribution of residuals for the response approximately follows the fitted normal distribution.

\subsubsection{Interaction plots}

Fig. 5 illustrates possible positive and negative effects of two variables interactions, respectively among the three parameters on UBS response. The non-parallel curves show the presence of interaction that can be estimated between rotation speed " $X_{1}$ " and friction time " $X_{3}$ " equal to 0.0052 , which means that the higher values of rotation speed affects UBS capacity when friction time is high and equal to $9 \mathrm{~s}$.

In addition, the effects of interactions such as rotation speed " $\mathrm{X} 1$ " and friction pressure " $\mathrm{X} 2$ ", friction pressure " $\mathrm{X} 2$ " and friction time "X3" are negligible due to parallel curves, which indicate the friction pressure $\mathrm{x} 2$ is the least significant or non-significant in the presence of other parameters simultaneously. 
These results confirm the previous finding obtained from Table 7, related to each parameter of influence on UBS process. Consequently, and in order to better understand the relationship between the three variables studied and the response which can related to UBS, a cubic graph is presented in Fig. 6.

The cubic graph demonstrates that increasing rotation speed $V$ from $2000 \mathrm{rpm}$ to $3000 \mathrm{rpm}$ and friction pressure from $20 \mathrm{MPa}$ to $40 \mathrm{MPa}$ considerably decreases UBS from $1288.51 \mathrm{MPa}$ to $1145 \mathrm{MPa}$ and 1288.51 MPa to $1255.41 \mathrm{MPa}$. The absence of parameter input of $\mathrm{x} 2$ (friction pressure) and speed of rotation of $x 1$ on the weld joint could be explained in the survey. Consequences of an increase in two previously located parameters influence the increase in the welded joint resistance until it reaches its limit and then decreases again. The reason is increased plastic deformation resulting from the application of excessive pressure and rotational speed [7].

\subsubsection{Response surface methodology (RSM)}

To further illustrate and discuss the effect of each factor and the interactions between these factors we were referred to the 3D response surface plots which were drawn as three dimensional plots of two factors while the other factor was kept constant. The 3-dimentional response surface for UBS (MPa) is shown in Fig. 7.

Fig. 7a represents UBS for different values of rotation speed $\left(X_{1}\right)$ and friction pressure $\left(X_{2}\right)$ for a constant friction time $\left(X_{3}\right)$. It is clearly that the response (UBS) increases when friction pressure $\left(X_{2}\right)$ increase independently. Fig. $7 b$ illustrates combined effect of rotation speed $\left(X_{1}\right)$ friction time $\left(X_{3}\right)$ for a constant value of friction pressure $\left(X_{2}\right)$ on UBS response. It can be seen that UBS increases as friction time $\left(X_{3}\right)$ decreases at friction pressure values. Therefore, Fig. 7c shows effect of friction pressure $\left(X_{2}\right)$ and friction time $\left(X_{3}\right)$ on UBS at constant value of rotation speed $\left(X_{1}\right)$. It can be seen that at high values of friction time t, UBS increases independently. As reported in previous work [15], with increasing friction time, hardness and tensile strength are increased. Those are influenced by augmentation of young's modulus and impact of friction time on welded joint also recognized in the micro-structural observation. Fig. 7 indicates UBS optimization results which can be achieved at lower values of rotation speed $\left(\mathrm{X}_{1}\right)$.

\subsubsection{Optimal design conditions using the desirability method}

The main object of this study was to find the optimal conditions in which UBS will be maximized, that desirability function was well used by Suich and Derringer in 1980 to solve the problems related to the optimization of industry-related multiple responses which have been applied in many studies [38-40]. Fig. 8 illustrates the prediction profiler function of studied parameter, it can be concluded that optimized conditions were rotation speed of $2000 \mathrm{rpm}$, friction pressure of $24.77 \mathrm{MPa}$ and friction time of $13 \mathrm{~s}$ for a predicted response UBS of $1406.892 \mathrm{MPa}$ with a desirability value of 0.991859 .

\subsection{Experimental results:}

\subsubsection{Micrographic and metallographic analysis:}


Fig. 9 shows an optical micrograph of welded joint for different zones, thermal affected zones (TAZ) and thermo-mechanical affected zones (TMAZ). As can be seen in Fig. 9, the welded joints were perfectly bonded; no cracks, low pores and no defect are observed. The grains are different in each affected zone, mainly resulting from the variation in temperature and pressure distribution. The grains are not uniform, elongated in the TAZ as shown in Fig. 9a \& 9c, and refined in TMAZ as shown in Fig. 9d \& 9f, cause of pressure application and heat due to thermo-mechanical action [41]. Furthermore, a reduction in ferrite and pearlite rate in each of steels is observed in compared to the base metals [24]. Ferrite/pearlite ratio remained the same in both steels after welding, i.e., the proportion of ferrite is predominant in $\mathrm{C} 45$ and conversely the rate of pearlite is higher in $16 \mathrm{NiCr} 6$.

Two flows are observed in the vicinity of the welded joint Fig. 9b \& 9e; the connection line of two steels plays role of an inverse axis of symmetry. Noticed also, that the absence of interface is enrolled by existence of continuity; within a good junction between the samples, the grain size has decreased significantly compared to TMAZ, which is a direct consequence of a dynamic recrystallization (DRZ) of the grains [42-43]. Indeed, the welding zone consists of equiaxed grains as a reason of sufficient DRZ is occurred [44].

Fig.10 represents SEM and EDX analysis performed at the central region of bonding interface and also at the ends of welded joint. The results are similar, with little variation in diffusion layer between the main chemical elements of $\mathrm{C} 45$ and $16 \mathrm{NiCr} 6$ steel. Fig. 10a reveals most relevant advantages of friction welding can be easily deduced. In fact, a significant reduction in the number of pores compared to base metals can be seen, probably a consequence of high plastic deformation [45]. Fig. 10b shows interdiffusion between $\mathrm{Ni}, \mathrm{Cr}, \mathrm{Si}$ and $\mathrm{Mn}$ characterizing the diffusion as the main bonding mechanism in the rotary friction welding process. The analysis records clearly diffusion of $\mathrm{Cr}$ and $\mathrm{Ni}$ through the interface from $16 \mathrm{NiCr} 6$ to $\mathrm{C} 45$. As a result of the diffusion, a gradual reduction of $\mathrm{Cr}$ and $\mathrm{Ni}$ in $16 \mathrm{NiCr} 6$ side adjacent to the interface and increasing of $\mathrm{Cr}$ and $\mathrm{Ni}$ in $\mathrm{C} 45$ side. Conversely is occurred for $\mathrm{Si}$ and $\mathrm{Mn}$ while these two last elements decrease in $\mathrm{C} 45$ interface side and increase in $16 \mathrm{NiCr} 6$ side, this result is in adequacy with references [7].

Fig. 11 shows EBSD map of welded joint of two samples S3(00-1) and $S 11(00+1)$. The maps show red, green and blue colour present 001, 011 and 111 planes respectively. It can be seen that the green colour dominates in the EBSD map for S3 welding parameters with low friction time and blue colour for S11 in high friction time, Fig. 11a \& 11b respectively, which indicates that the grain orientation mainly concentrates in the normal direction of crystallographic plane $\{101\}$ for S3 and $\{111\}$ for S11.

For low parameters the grain size is not uniform than for high parameters, no special high-density orientation distribution. The statistical result of grain indicates that the proportion of average diameter grain size is 3.32 um in parameters with low friction time (00-1) and 2.15 um for parameter with high friction time $(00+1)$. The origin of finer grains in the high friction time input joint can be attributed to micro-structural evolution during RFW.

\subsubsection{Mechanical behaviour}

Page 12/25 
RSM study shows that the most significant parameter influencing UBS is the friction time. In this perspective present work studied the mechanical behaviour of welded joint at the parameters of (0.0.-1) $(0.0 .0)$ and $(0.0 .+1)$, to demonstrate the contribution of friction time to weld joint behaviour. Valuable information's on mechanical behaviour are provided using the measurements of hardness, wear and nano-indentation at different stages of the friction time.

Vickers micro-hardness distributions in specimens previously selected are shown in Fig. 12a. The measurements were carried out from $\mathrm{C} 45$ side to $16 \mathrm{NiCr} 6$ side. As expected, the micro-hardness reaches maximum values close to the interface and decreases very rapidly from TMZA until base metal. Fig. 12a shows a comparison between welded specimens with high, low and medium friction time, as observed from this figure can recognize an increase of micro-hardness from t: $9 \mathrm{~s} \mathrm{Hv} 360 \pm 10$ to t: $11 \mathrm{~s} \mathrm{Hv} 430 \pm$ 10 and then decrease in t: $13 \mathrm{~s}$ to achieve Hv350 \pm 10 where the base metal on both $\mathrm{C} 45$ and $16 \mathrm{NiCr} 6$ were approximately $\mathrm{Hv} 200 \pm 10$ for $\mathrm{C} 45$ and $\mathrm{Hv} 220 \pm 10$ for $16 \mathrm{NiCr} 6$, this increasing may have caused by micro-structural evaluations around the interface, diffusion of elements on the sides, work hardening, dislocation and refinement of grains.

The literature demonstrates a similar hardness profile for dissimilar material couples [46]. Microhardness at $\mathrm{t}: 13 \mathrm{~s}$ friction pressure, represent approximately $65 \%$ up than microhardness of the base metals which is very low compared to other fusion welding process, [24]. The decrease in hardness at t: $13 \mathrm{~s}$ which can be attributed to the decrease in temperature generated. In fact, after the plastic deformation, a reduction in friction is generally observed. The same behaviour has seen in Fig. 12c. The nano-indentation applied on the same samples shows a similar behaviour where the displacement into surface at $\mathrm{t}: 11 \mathrm{~s}$ is less than those at t: $9 \mathrm{~s}$ and $13 \mathrm{~s}$, which leads us to suppose that the hardness at 9 and $11 \mathrm{~s}$ friction time is similar.

Nevertheless, Fig. 12d shows better understand the impact by increasing of welding time on the mechanical behaviour. Noticed there is a clear increasing of young's modulus of $260 \mathrm{GPa}$ compared to the lower friction times, t: $11 \mathrm{~s}$ is $210 \mathrm{GPa}$ and t: $9 \mathrm{~s}$ is $230 \mathrm{GPa}$. Fig. 12b illustrates three different scratch profiles. It can be seen at the interface with substrate various coefficient of friction with change of welding time, also observed a deep fluctuations in both $\mathrm{C} 45$ and $16 \mathrm{NiCr} 6$ sides that may be related to presence of pores in that areas and can easily notice the decrease in these fluctuations at the weld interface, which maybe equates to decrease in that pores and confirms with Fig. 10a. Thus, close to the interface, a low deformation is observed due to the presence of TAZ, which reveals a high microhardness and that for all welded samples.

Regarding to the behaviour as a function of friction time variation, noticed that the friction coefficient decreases in the welded zone, which can be explained by high grains refinement. On the other hand, the variation of friction coefficient shows an increase at $t: 11 \mathrm{~s}$, which leads us to suppose that the grains have coalesced, this coefficient relapses at $\mathrm{t}: 13 \mathrm{~s}$, due to grain disintegration formed after $\mathrm{t}: 11 \mathrm{~s}$.

Bending fracture surface micrographs by SEM were performed on specimen S11 (0.0.1) and S7 (1.1.-1). As presented in Fig. 13, bending specimen S11 shows that the fracture mostly takes place at rotary part 
(C45 side), with elongated grain structure at fracture zone, the SEM observation indicates a river like pattern that commonly attributed to the brittle fracture [47]. The elongated structure at some region shows ductile fracture [48]. Fig. 13a shows detailed view of the fracture surface in which the structure is elongated and dislocated, which's remarkable from one zone to another. Fig. 13b and 13c illustrate fracture surface for steels are with half bubbles or cups, the latter are characteristic of a ductile fracture and are formed by growth of cavities in the material. Ductile fracture is preceded by significant plastic deformation, often resulting in cups linked to decohesion around inclusions that act as initiation of fracture. Fracture surfaces show the presence of several cups of sizes between 5 to $10 \mu \mathrm{m}$. These cups extend in the tensile direction. These cavities gather and coalesce in order to accelerate the fracture.

\section{Conclusion}

In this study, the impact of Rotary friction welding parameters (rotational speed, friction pressure and friction time) on the ultimate bending strength MPa of welded C45 to $16 \mathrm{NiCr} 6$ are investigated using RSM technique, microstructural analyses and mechanical tests. The main conclusions obtained can be summarized as following below.

- Studying the impact of welding parameters and trying to optimize, the RSM results shows the most effective parameters on the UBS of the joints is friction time, respectively. However, the combined rotary friction welding parameters impact on the UBS of joints differently regarding to microstructure change. 3D response surface interaction reveals that normal friction time - friction pressure interaction is the most influencing in UBS. On the other hand, by RFW at a rotational speed, friction pressure, and friction time of $2000 \mathrm{rpm}, 24.77 \mathrm{MPa}$, and 13 seconds, the maximum value of 1406.89 MPa can be obtained for UBS of the joints.

- Microstructural properties of welding joint at low and high friction time show a great difference in the mechanical behaviour regarding to the deformation of grain which become more refined by increasing of friction time, this behaviour results from it a clear increase of young's modulus which reaches $260 \mathrm{GPa}$ at $\mathrm{t}=13$ seconds representing an augmentation of $13 \%$ compared to $t=11$ seconds and $23 \%$ compared to $t=9$ seconds.

\section{Declarations}

Funding (information that explains whether and by whom the research was supported) Not applicable Conflicts of interest/Competing interests (include appropriate disclosures) Not applicable

\section{Availability of data and material (data transparency)}

The authors confirm that the data supporting the findings of this study are available within the article. The raw data that support the findings of this study are available upon a reasonable request.

Code availability (software application or custom code) 
Not applicable (jmp 13 design of experiments "free version")

\section{Ethics approval (include appropriate approvals or waivers) Not applicable}

\section{Consent to participate (include appropriate statements)}

The authors state that the work was carried out in collaboration with all members

\section{Consent for publication (include appropriate statements)}

The authors agree and wish that the paper will be published in your journal

\section{Authors' contributions (optional: please review the submission guidelines from the journal whether statements are mandatory)}

Authors contribution Youcef Belkahla: conceptualization, experimental work, data curation, and writing (original draft preparation). Azzeddine Mazouzi: investigation, experimental work, reviewing, and editing. Seif El Islam Lebouachera: software and analysis of all the obtained raw data of response surface methodology. Ammar Jabbar Hassan: methodology, reviewing and editing (final draft), review, and editing. Martin Fides: supervision and project administration. : validation. Pavol Hvizdoš: methodology, validation, and involved in the discussion. Billel Cheniti: methodology and reviewing Djamel Miroud: project administration.

\section{References}

1. Brown AL, Campione JC (1981) Inducing flexible thinking: The problem of access. Intelligence and learning. Springer, pp 515-529

2. Klimpel A (1998) The problem of welding cast irons is examined taking the example of a spheroidal cast iron. Welding international 12(1):20-24

3. Lu C, Xiao S, Li X, Gao L (2016) An effective multi-objective discrete grey wolf optimizer for a realworld scheduling problem in welding production. Adv Eng Softw 99:161-176

4. Didžiokas R, Januteniene J, Jonaityte J (2008) The impact of the internal welding defects on the joint strength. Transport 23(3):240-244

5. Sahin M (2009) Joining of stainless steel and copper materials with friction welding. Industrial lubrication and tribology

6. Meshram S, Mohandas T, Reddy GM (2007) Friction welding of dissimilar pure metals. J Mater Process Technol 184(1-3):330-337

7. Alves EP, Piorino Neto F, An CY (2010) Welding of AA1050 aluminum with AISI 304 stainless steel by rotary friction welding process. Journal of Aerospace Technology Management 2(3):301-306

8. Kurt A, Uygur I, Paylasan U (2011) Effect of friction welding parameters on mechanical and microstructural properties of dissimilar AISI 1010-ASTM B22 joints. Welding journal 90(5):102-106 
9. Bouarroudj El, Chikh S, Abdi S, Miroud D (2017) Thermal analysis during a rotational friction welding. Appl Therm Eng 110:1543-1553

10. Umanath K, Palanikumar K (2015) Influence of process parameter on microstructural characteristics and tensile properties of friction welded ASS304L alloy. Applied Mechanics and Materials. Trans Tech Publ, pp 745-750

11. Seshagirirao B, Sivaramakrishna V, Saikrishnaprasad G (2015) Experimental Investigation of Rotary Friction Welding Parameters of Aluminum (H-30) and Mild Steel (AISI-1040). International Journal of Innovative Research in Science Engineering Technology 4(5):2920-2925

12. Jin F, Li J, Liao Z, Li X, Xiong J, Zhang F (2018) The corona bond response to normal stress distribution during the process of rotary friction welding. Welding in the World 62(5):913-922

13. Wang G, Li J, Xiong J, Zhou W, Zhang F (2018) Study on microstructure evolution of AISI 304 stainless steel joined by rotary friction welding. Welding in the World, pp: 1-7

14. Özdemir N, Sarsılmaz F, Hasçalık A (2007) Effect of rotational speed on the interface properties of friction-welded AISI 304L to 4340 steel. Mater Design 28(1):301-307

15. Ates H, Kaya N (2014) Mechanical and Microstructural Properties of Friction Welded AISI 304 Stainless Steel to AISI 1060 Steel AISI 1060. Arch Metall Mater 59(3):841-846

16. Jabbar Hassan A, Boukharouba T, Miroud D (2021) Concept of forge application under effect of friction time for AISI 316 using friction welding process. The International Journal of Advanced Manufacturing Technology 112:2223-2231

17. Jabbar Hassan A, Boukharouba T, Miroud D, Titouche N, Ramtani S (2021) Direct Drive Friction Welding Joint Strength of AISI 304. IJE Transactions C: Aspects 34(3):184-191

18. Jabbar Hassan A, Boukharouba T, Miroud D (2020) Friction welding of AISI 304: effect of friction time on micro-structure, micro-hardness and tension-compression properties. Acta Metall Slovaca 26(3):78-84

19. Bezerra MA, Santelli RE, Oliveira EP, Villar LS, Escaleira LA (2008) Response surface methodology (RSM) as a tool for optimization in analytical chemistry. Talanta 76(5):965-977

20. Mazouzi A, Rezzoug A, Cheniti B et al (2021) Impact of wear parameters on NiCr-WC10Co4Cr and WC10Co4Cr HVOF sprayed composite coatings using response surface methodology. Int J Adv Manuf Technol 114:525-539

21. Lebouachera S-E-I, Ghriga MA, Salha GB et al (2021) Optimization of zero-shear viscosity for HPAMPolystyrene microspheres formulations through experimental design approach. J Polym Res 28:135

22. et al (2019) Experimental design methodology as a tool to optimize the adsorption of new surfactant on the Algerian rock reservoir: cEOR applications. Eur. Phys. J. Plus 134: 436

23. Heidarzadeh A (2019) Tensile behavior, microstructure, and substructure of the friction stir welded 70/30 brass joints: RSM, EBSD, and TEM study. Archives of Civil Mechanical Engineering 19(1):137146 
24. SELVAMANI ST, PALANIKUMAR K (2014) Optimizing the friction welding parameters to attain maximum tensile strength in AISI 1035 grade carbon steel rods. Measurement 53:10-21

25. Paventhan R, Lakshminarayanan PR, Balasubramanian V (2011) Fatigue behaviour of friction welded medium carbon steel and austenitic stainless steel dissimilar joints. Mater Des 32(4):18811894

26. Winiczenko R, Kaczorowski M (2013) Friction welding of ductile iron with stainless steel. J Mater Process Technol 213:453-462

27. Kim HG, Kim SM, Lee JY et al (2014) Microstructural evaluation of interfacial intermetallic compounds in Cu wire bonding with Al and Au pads. Acta Mater 64:356-366

28. Bezerra MA, Santelli RE, Oliveira EP, Villar LS, Escaleira LA (2008) Response surface methodology (RSM) as a tool for optimization in analytical chemistry. Talanta 76(5):965-977

29. Montgomery DC (2017) Design and analysis of experiments. John wiley \& sons

30. Dey HC, Ashfaq M, Bhaduri AK, Rao KP (2009) Joining of titanium to 304L stainless steel by friction welding. Journal of Materials Processing Technology 209:5862-5870

31. Kimura M, Suzuki K, Kusaka M, Kaizu K (2017) Effect of friction welding condition on joining phenomena, tensile strength and bend ductility of friction welded joint between pure aluminium and AISI 304 stainless steel. Journal of Manufacturing Processes 25:116-125

32. Oliver WC, Pharr GM (1992) An improved technique for determining hardness and elastic modulus using load and displacement sensing indentation experiments. J Mater Res 7(6):1564-1583

33. Fukumoto S, Tsubakino H, Okita K, Aritoshi M, Tomita T (2000) Amorphization by friction welding between 5052 aluminum alloy and 304 stainless steel. Scr Mater 42:807-812

34. Lin R, Yin G (2015) Bayes factor and posterior probability: complementary statistical evidence to pvalue. Contemp Clin Trials 44:33-35

35. Gujarati DN (2004) Econométrie, Traduction de la 4ième édition américaine par Bernard Bernier. De Boeck, Bruxelles

36. Hank D et al (2014) Optimization of phenol adsorption onto bentonite by factorial design methodology. J Ind Eng Chem 20(4):2256-2263

37. Ghaedi M et al (2018) Removal of methylene blue by silver nanoparticles loaded on activated carbon by an ultrasound-assisted device: optimization by experimental design methodology. Res Chem Intermed 44(5):2929-2950

38. Derringer G (1980) Simultaneous optimization of several response variables. Journal of quality technology 12(4):214-219

39. Candioti LV et al (2014) Experimental design and multiple response optimization. Using the desirability function in analytical methods development. Talanta 124:123-138

40. Regti A et al (2017) Use of response factorial design for process optimization of basic dye adsorption onto activated carbon derived from Persea species. Microchem J 130:129-136 
41. Paventhan R, Lakshminarayanan PR, Balasubramanian V (2011) Fatigue behavior of friction welded medium carbon steel, Fatigue behaviour of friction welded medium carbon steel and austenitic stainless steel dissimilar joints. Mater Des 32(4):1881-1894

42. Behnken H, Hauk V (2009) Micro-residual stresses caused by deformation, heat, or their combination during friction welding. Mater Sci Eng 289:60-69

43. ÖZDEMIR N, SARSILMAZ F, HASÇALIK A (2007) Effect of rotational speed on the interface properties of friction-welded AISI 304L to 4340 steel. Mater Design 28(1):301-307

44. Zhu Y, Zhu Z, Xiang Z, Yin Z, Wu Z, Yan W (2009) Microstructural evolution in 4Cr 10 Si 2 Mo at the 4Cr 10 Si 2 Mo/Nimonic 80A weld joint by inertia friction welding. J Alloys Compd 476(1):341-347

45. UDAY MB, AHMAD FAUZI MN, ZUHAILAWATI H et al (2010) Advances in friction welding process: a review. Science technology of Welding Joining 15(7):534-558

46. MESHRAM SD, MOHANDAS T, Madhusudhan REDDYG (2007) Friction welding of dissimilar pure metals. J Mater Process Technol 184(1-3):330-337

47. HANDA A, CHAWLA V (2013) MECHANICAL CHARACTERIZATION OF FRICTION WLDED DISSIMILAR STEELS AT 1000 RPM. Materials Engineering-Materiálové inžinierstvo (MEMI) 20(3):102-111

48. WINICZENKO R, KACZOROWSKI M (2013) Friction welding of ductile iron with stainless steel. J Mater Process Technol 213(3):453-462

\section{Figures}
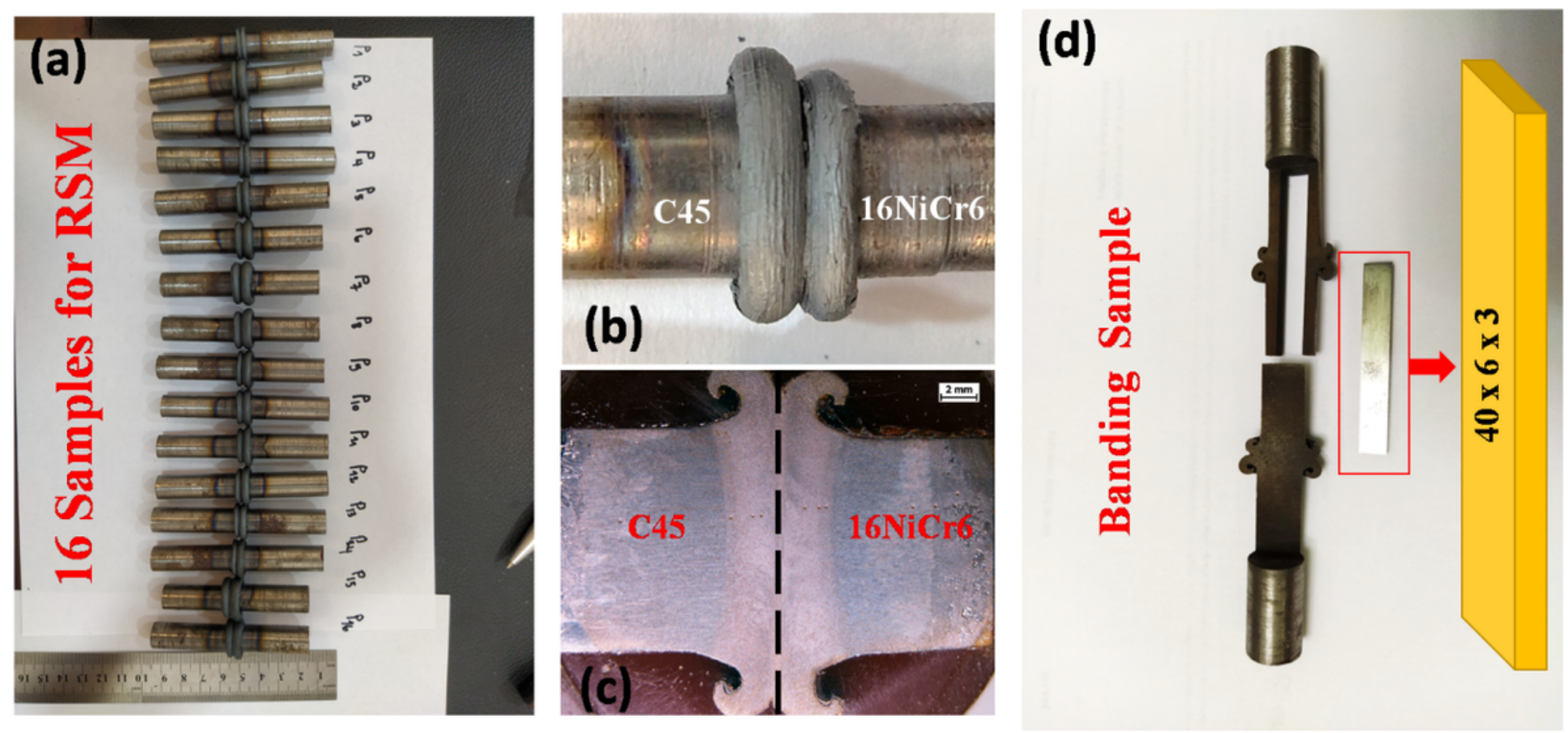

\section{Figure 1}


Photographs of friction welded joints and tested specimens. a 16 samples for RSM, b flash form of sample, $\mathrm{c}$ macrograph of welding joint, and d bending sample.
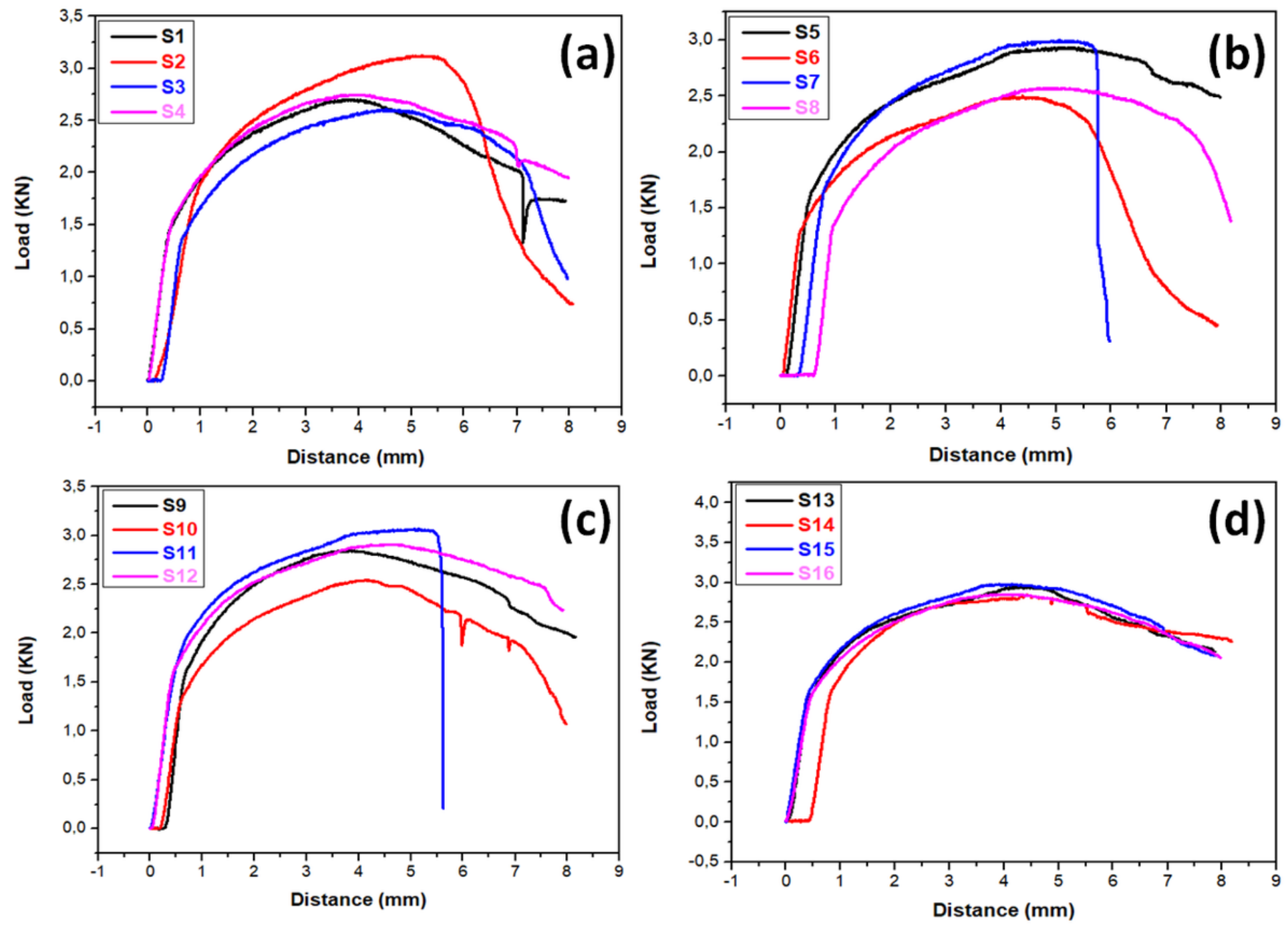

Figure 2

Load- displacement curves for bending test for all samples. a S1-S4, b S5-S8, c S9-S12, and d S13 S16

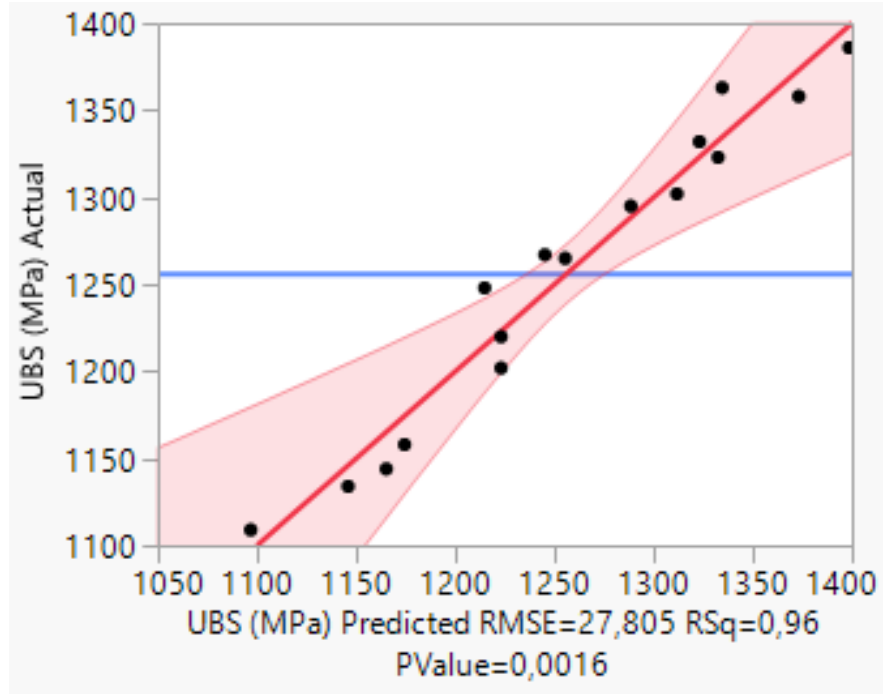


Figure 3

Plot of predicted versus experimental responses of UBS (MPa)

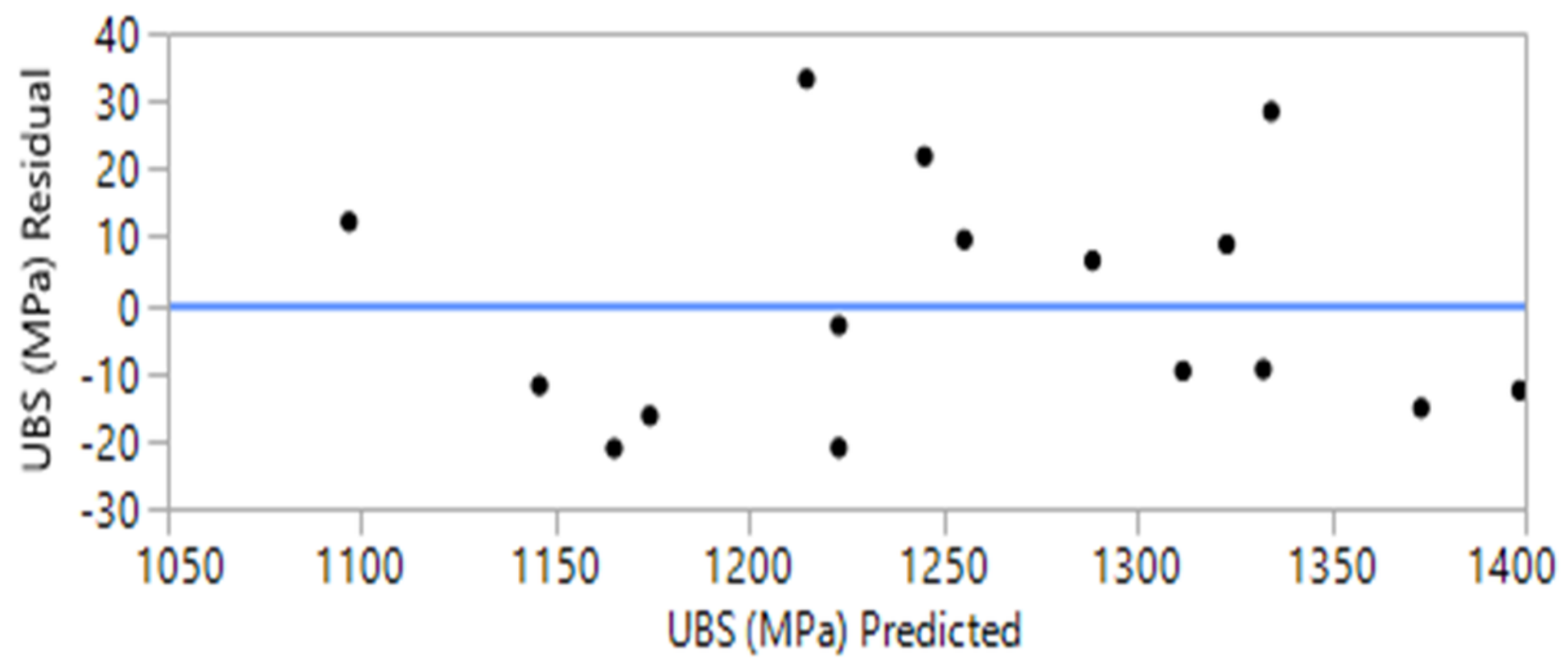

Figure 4

Residual plot of Ultimate bending strength UBS in MPa in the model

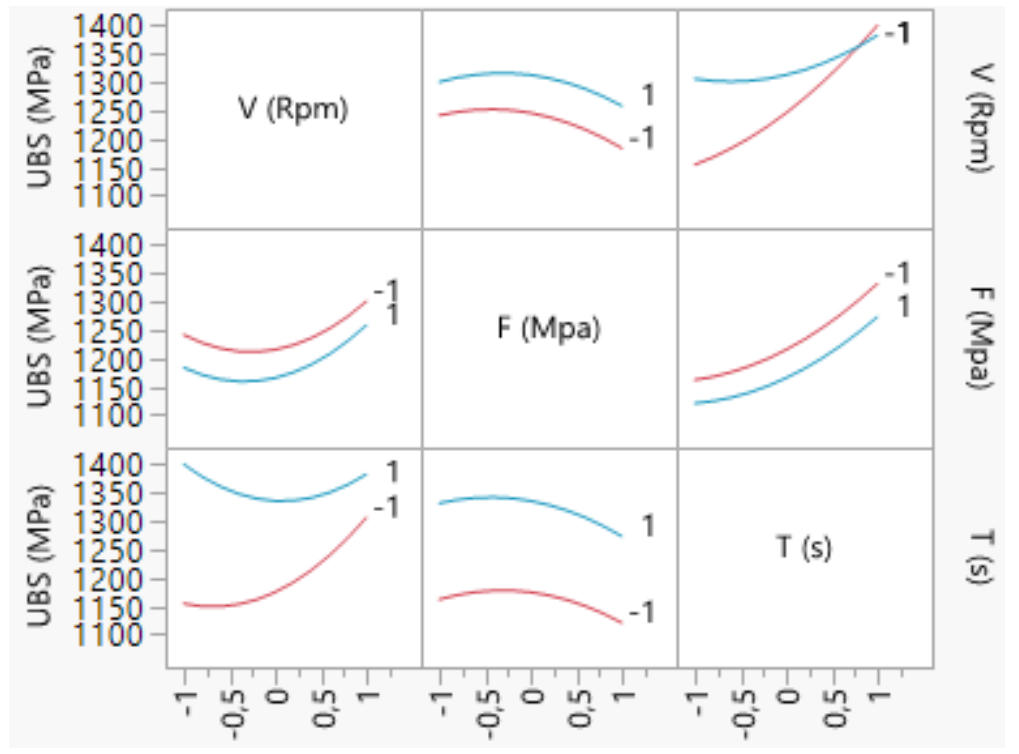

Figure 5

Interaction effect plots of the UBS (MPa) vs. studied parameters 


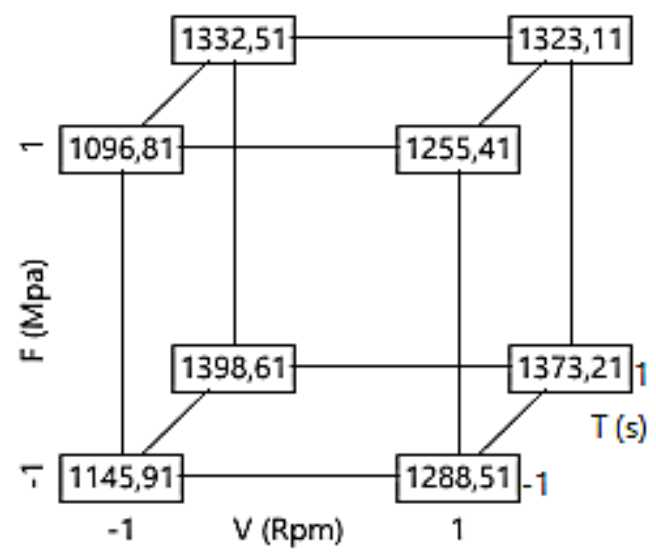

Figure 6

Cube of USB (MPa) considering the interactions
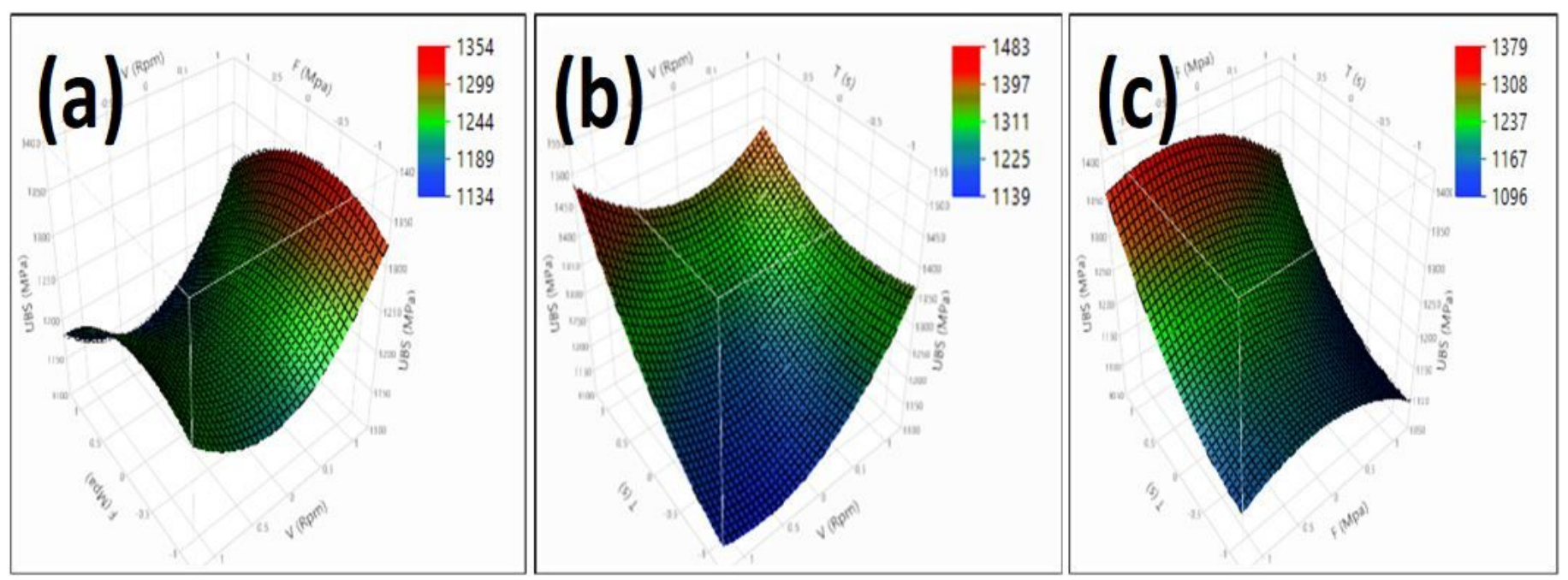

Figure 7

Response surface contour (3D) of UBS (MPa) showing combined effect of three welding parameters ( $\mathrm{x} 1$, $\mathrm{x} 2, \mathrm{x} 3)$ 


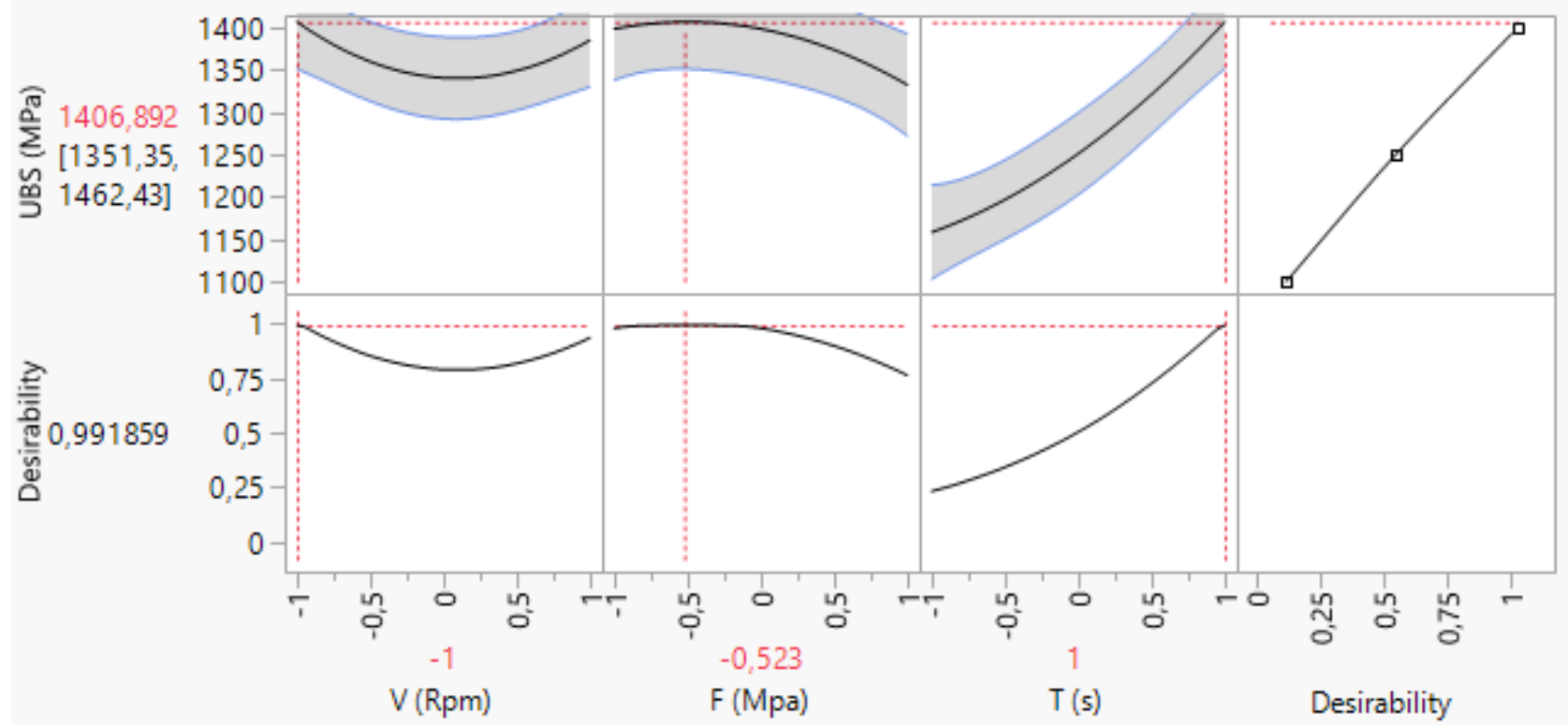

Figure 8

Prediction profiler of Ultimate Bending Strenght MPa function
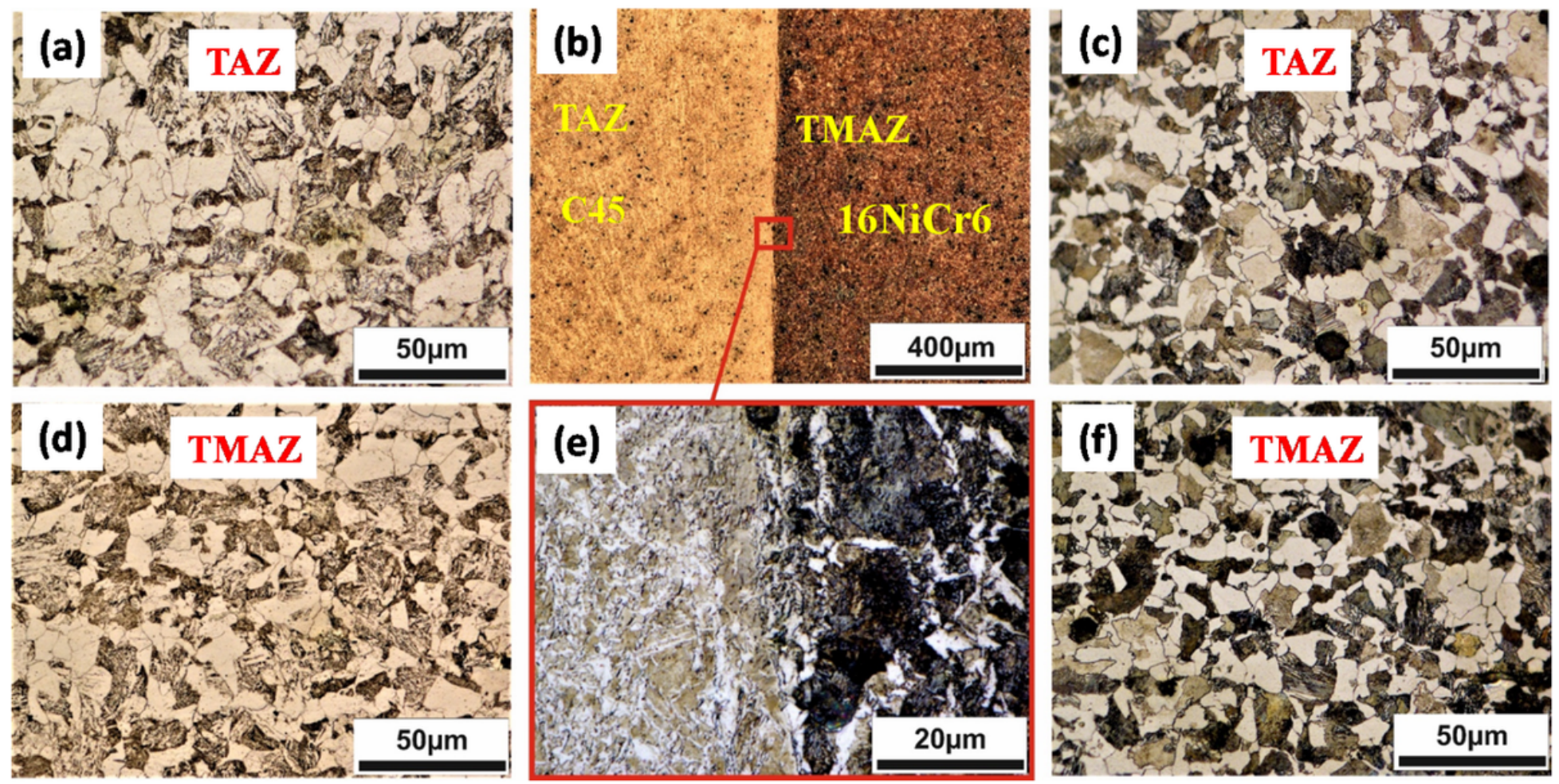

Figure 9

Optical micrographs for welded joint. a TAZ for AISI 1045 side, b global micrograph shows welded joint, c TAZ for 16 NC6 side, d TMAZ for AISI 1045 side, e dynamic recrystallization zone DRZ, and f TMAZ for 16NC6 side 

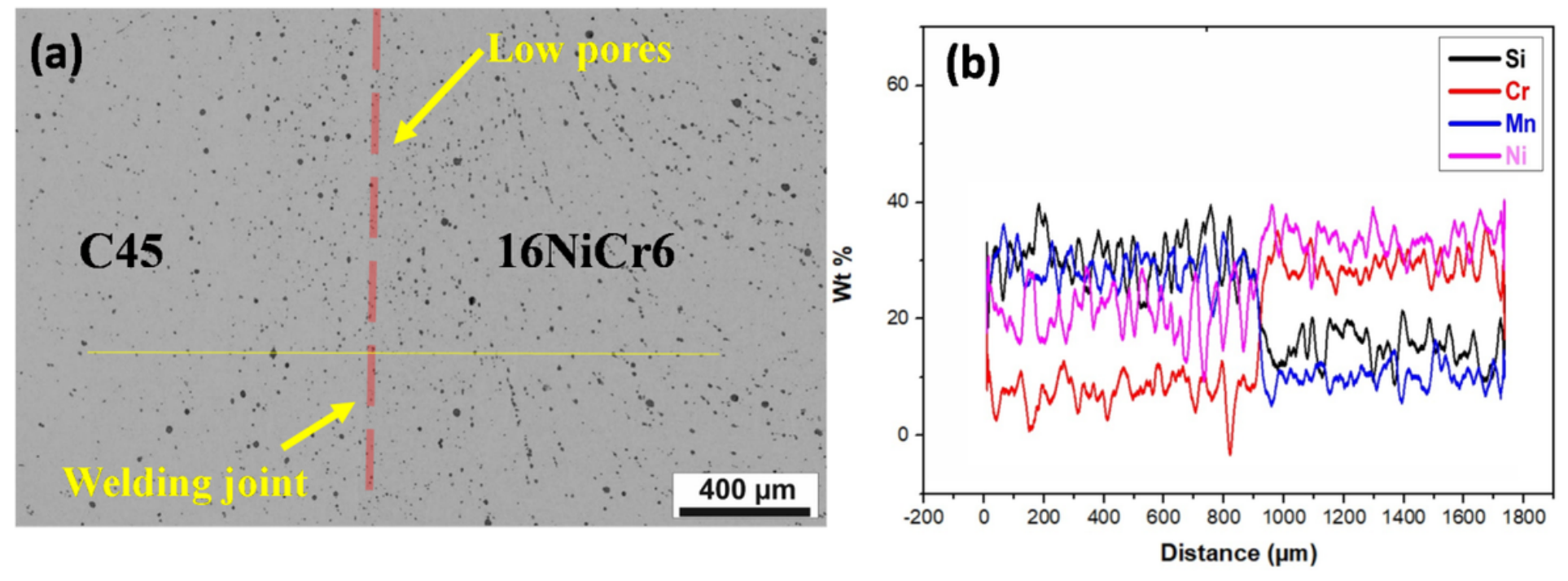

Figure 10

SEM images and EDS micrograph for welded joint
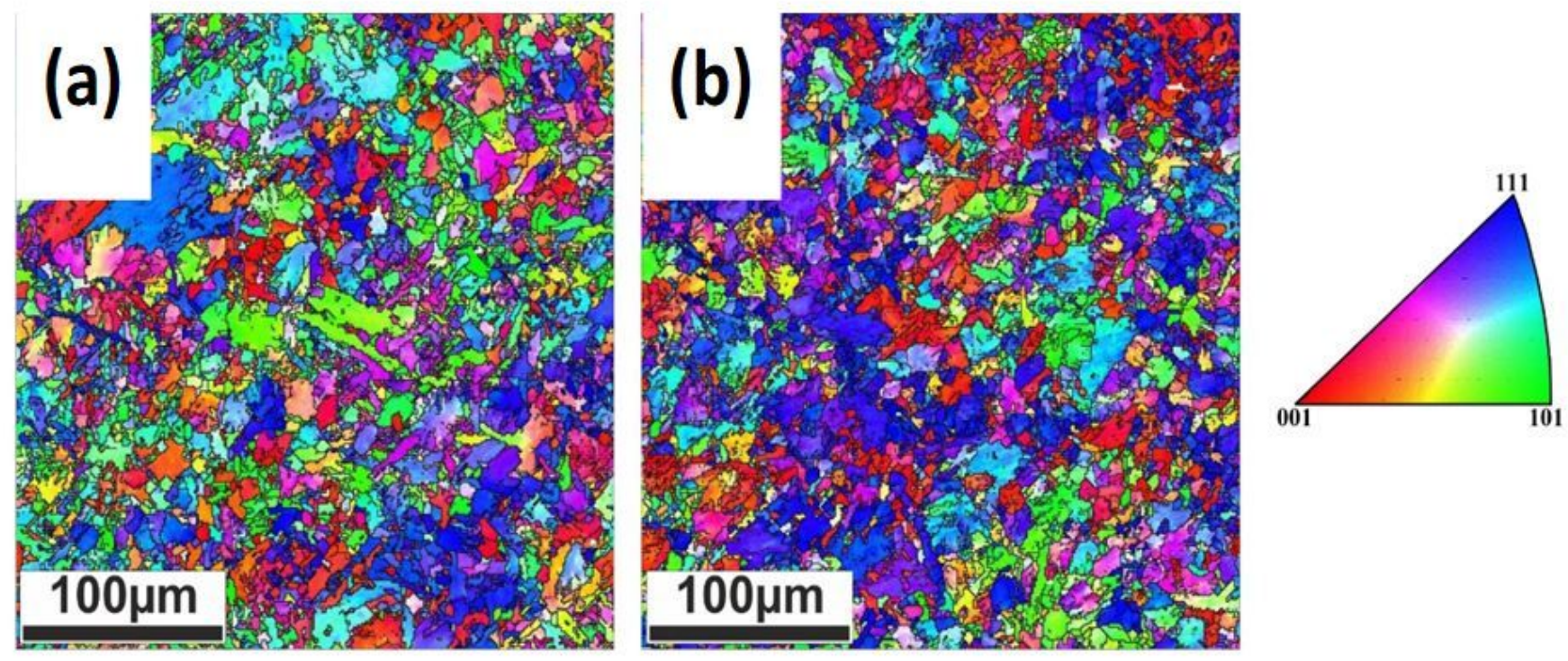

Figure 11

EBSD map for welded joints. a S3, and b S11 

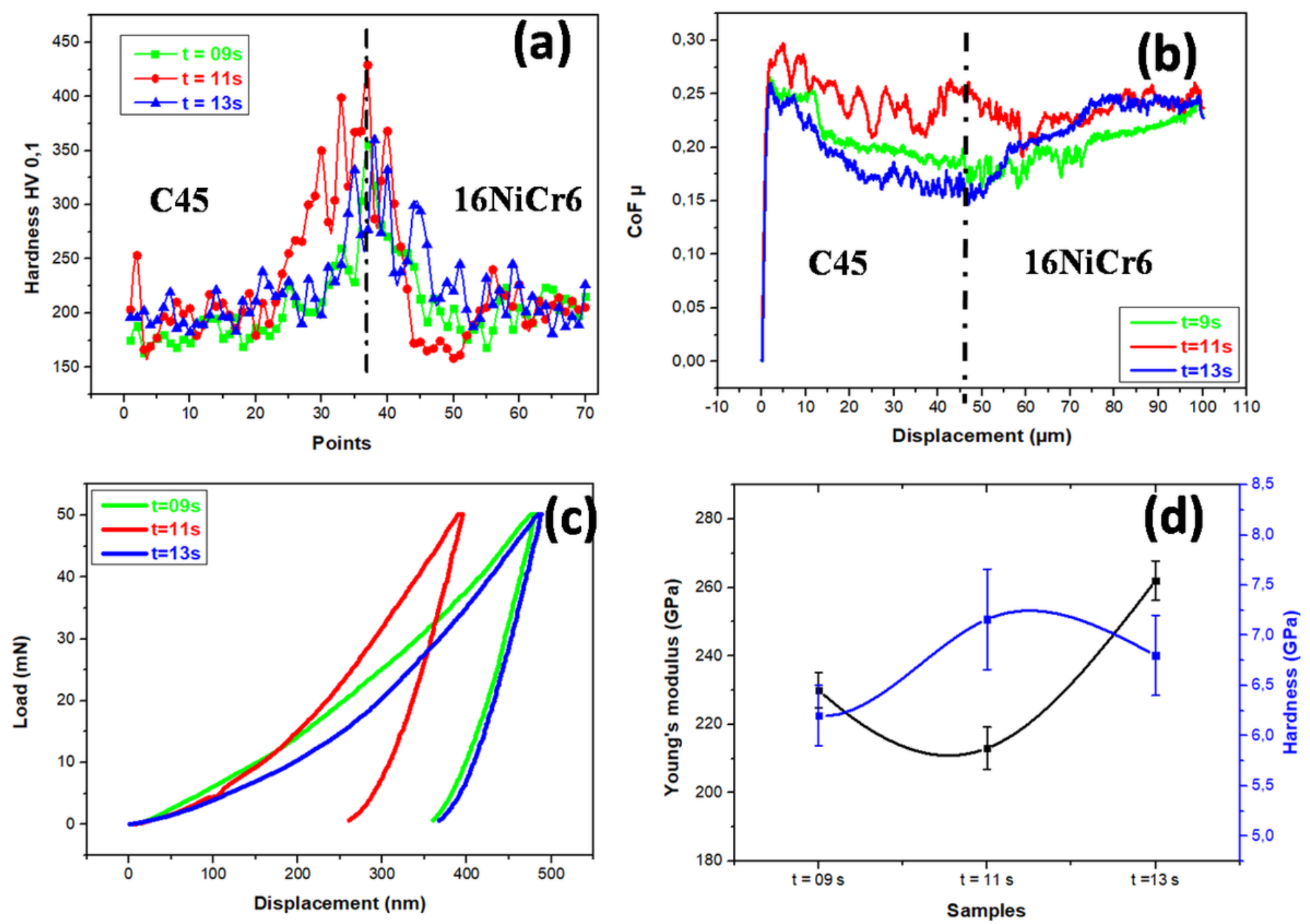

Figure 12

Influence of friction time on mechanical behavior. a Vickers micro-hardness, b scratch, c Nanoindentation, and d interaction between friction time, young's modulus (GPa) and hardness (GPa) 


\section{Bending sample}
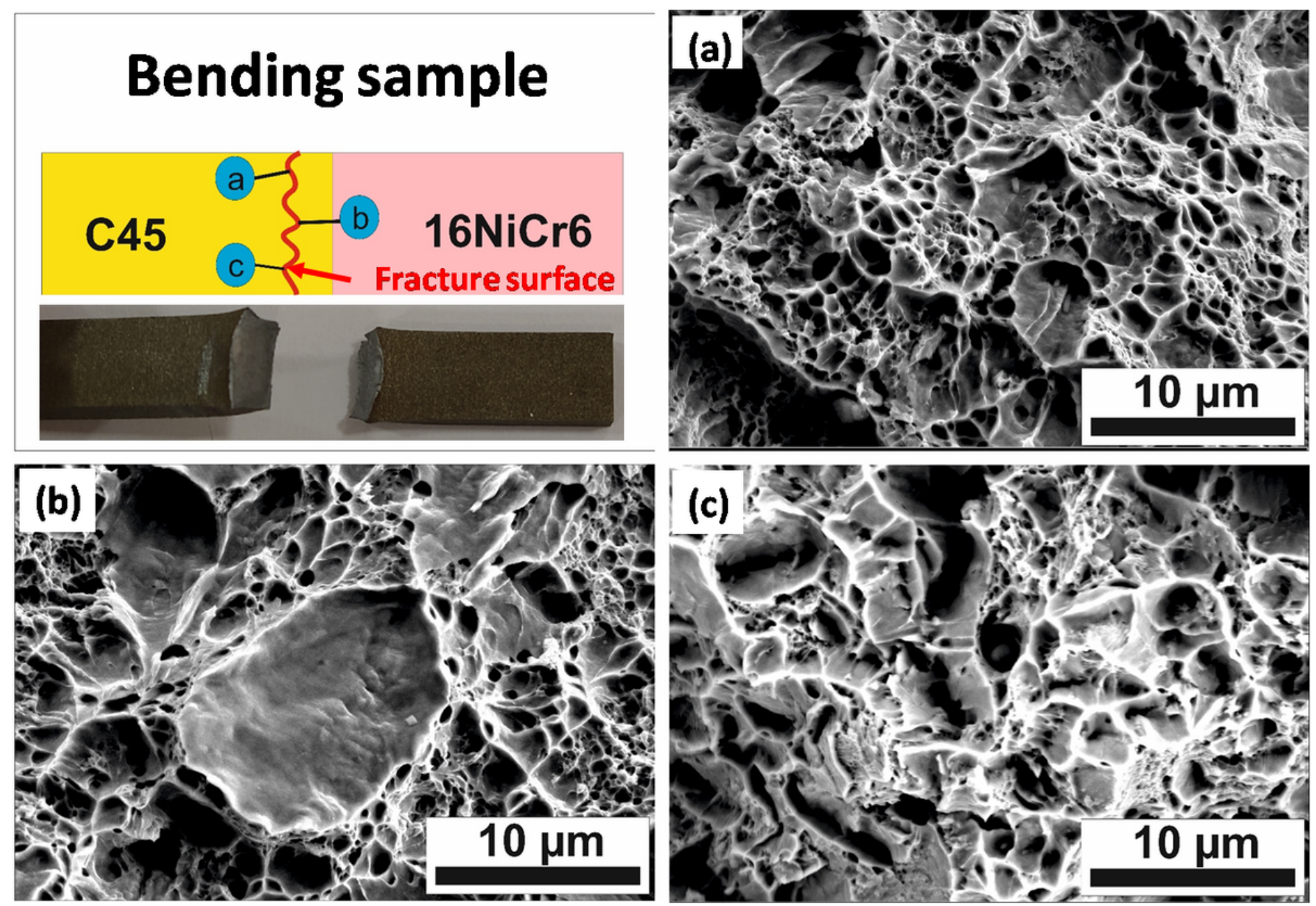

Figure 13

Bending fracture surface morphology for cracked sample

\section{Supplementary Files}

This is a list of supplementary files associated with this preprint. Click to download.

- GraphicalAbstract.jpg 